Check for updates

Cite this: RSC Adv., 2019, 9, 9870

\title{
Mechanisms of isomerization and oxidation in heated trilinolein by DFT method $\dagger$
}

\author{
Changmo Li, ab Guiting Ma, ab Yunping Yao, (D) *ab Wentao Liu, ${ }^{\text {ab }}$ Hang Zhou, ${ }^{\text {ab }}$ \\ Hongyan $\mathrm{Mu}^{\mathrm{d}}$ and Shuo Wang ${ }^{\star \mathrm{c}}$
}

In order to investigate the molecular mechanisms of the heat-induced cis/trans isomerization and oxidative cleavage of trilinolein, a highly purified sample was heated at a range of temperatures $(120,140,160,180$, $200,220^{\circ} \mathrm{C}$ ) for $5 \mathrm{~h}$. The reaction process of cis/trans isomerization of C18:2 was studied by a combination of the gas chromatogram (GC) method with density functional theory (DFT). When trilinolein was heated to $180^{\circ} \mathrm{C}$, a small amount of trans/trans $\mathrm{C} 18: 2$ was obtained $\left(0.074 \mathrm{mg} \mathrm{g}^{-1}\right)$. As the temperature increased to $220^{\circ} \mathrm{C}$, the amount of trans $\mathrm{C} 18: 2$ reached $0.198 \mathrm{mg} \mathrm{g}^{-1}$. This study shows that $\mathrm{C} 18: 2-9 \mathrm{c} 12 \mathrm{t}$ and $\mathrm{C} 18: 2-$ $9+12 \mathrm{c}$ were the main trans fatty acids in heated trilinolein. The molecular mechanisms of isomerization and oxidative cleavage were verified by Gaussian $09 \mathrm{~W}$ software. All the geometry was optimized using DFT at the B3LYP/6-31*G level. The energy difference between cis and trans linoleic acid was equal to $6.2 \mathrm{~kJ} \mathrm{~mol}^{-1}$. Therefore, vegetable oil with a higher linoleic acid content should be maintained at $140{ }^{\circ} \mathrm{C}$

or less to avoid the formation of trans linoleic acid.

Received 14th January 2019

Accepted 23rd February 2019

DOI: $10.1039 / c 9 r a 00328 b$

rsc.li/rsc-advances

\section{Introduction}

Linoleic acid is a polyunsaturated fatty acid containing two double bonds, mainly found in safflower oil, sunflower oil, soybean oil, corn oil and other plant oils. Trans isomers and oxidative cleavage products can be easily formed during industrial food manufacturing processes and human consumption owing to its diene unsaturated geometric configuration. ${ }^{1}$ Thermal oxidation is the principal route of isomerization and degradation of oils and fats. ${ }^{2}$ The cis double bonds are rotated to produce trans double bonds for the formation of trans fatty acids. Simultaneously, secondary products produced by oxidative cleavage can affect the color, taste, flavor and morphology of the oils, and greatly reduce the nutritional quality and safety of the oils and fats. It has been reported that trans fatty acids are closely linked to the risk of chronic diseases. ${ }^{3,4}$ Trans fatty acids affect the activities of macrophages, leading to an increase in pro-inflammatory reactions and the

${ }^{a}$ Demonstration Center of Food Quality and Safety Testing Technology, Tianjin University of Science and Technology, Tianjin 300457, China. E-mail: yaoyunping1314@163.com; Fax: +86-22-60912419; Tel: +86-22-60912419

${ }^{b}$ State Key Laboratory of Food Nutrition and Safety, Key Laboratory of Food Nutrition and Safety, Ministry of Education, College of Food Engineering and Biotechnology, Tianjin University of Science and Technology, 300457, Tianjin, China

'Tianjin Key Laboratory of Food Science and Health, School of Medicine, Nankai University, Tianjin,300071, China.E-mail: s.wang@tust.edu.cn

${ }^{d}$ College of Food Science and Engineering, Qingdao Agricultural University, 700 Changcheng Road, Qingdao 266109, Shandong, P. R. China

$\dagger$ Electronic supplementary information (ESI) available. See DOI: $10.1039 / \mathrm{c} 9 \mathrm{ra} 00328 \mathrm{~b}$ occurrence of atherosclerosis. ${ }^{5-7}$ Trans fatty acids can decrease the level of high-density lipoprotein cholesterol (HDL) and increase the level of low-density lipoprotein cholesterol (LDL), thereby increasing the risk of coronary heart disease..$^{8-10}$ It is well known that primary oxidation compounds or hydroperoxides can be formed in the oxidation of edible oils at high temperature or in the presence of metals, which can then be degraded to secondary oxidation compounds. Thus via $\beta$-scission of alkoxy radicals fatty acid hydroperoxides can form aldehydes, ketones, hydrocarbons, alcohols, acids, esters, and aromatic compounds. ${ }^{2,11-14}$ Among these decomposition products aldehydes are dominant and are highly toxic and reactive. ${ }^{15-18}$ Hexanal is an aldehyde which is closely linked to potential immunotoxic effects on the human pulmonary system or pulmonary inflammatory/immune responses to the respiratory system. ${ }^{19}$ There is a close link between women's lungs, 2,4decadienal and the development of adenocarcinoma, due to their frequent exposure to oil smoke during deep-frying processes. ${ }^{20}$ There is a harmful effect on the health of cooks since these volatile aldehydes are scattered in the air.

Previous studies reported that thermal induction causes the double bond to undergo a certain amount of isomerization. Christy analyzed the content of trans isomers in edible oils and fats using infrared spectroscopy (IRS) and gas chromatography (GC). ${ }^{12}$ There was no clear explanation of the reason why the isomerization of $9 \mathrm{t} 12 \mathrm{c}$ requires less activation energy than the isomerization of 9c12t. Li A. ${ }^{21}$ reported on the mechanism of cis/ trans isomerization during the thermal treatment of soybean oil. GC was used to determine the isomerization products, and density functional theory (DFT) was used to obtain the process 
of cis/trans isomerization of trilinolein. No further studies to analyze the formation mechanism of oxidative cleavage products during heating could be found. Furthermore, other ingredients in soybean oil samples have an impact on the experimental results. Although isomerization of trilinolein has been reported in some papers, little was known about the isomerization and oxidative cleavage mechanism in pure trilinolein. Simultaneously, correlations among heating temperature, activation energy and the isomerization products of pure trilinolein have not been investigated. Furthermore, there is a scarcity of literature on the isomerization mechanism of trilinolein using experimental and simulation methods. In order to supplement the research and fill the gaps in this field, in this study isomerization and oxidative cleavage mechanisms were explored by GC, high-performance liquid chromatography (HPLC) and DFT methods.

DFT is widely used in physical chemistry, particularly in the study of the nature of molecules and material chemistry systems. It has been applied to study the mechanism of trans fatty acids under heating conditions in triolein by our research team..$^{22}$ The purpose of this paper is to study the isomerization temperature of linoleic acid and to determine the type and content of trans linoleic acid at various temperatures. The cis/ trans isomers were determined by HPLC and the decomposition products were determined by GC. The geometrical parameters of different configurations of linoleic acid and the energy of isomerization and oxidative cleavage of linoleic acid were calculated by DFT. The ratios of intermediates and transition states were verified by intrinsic reaction coordinates (IRCs). The aim of the study of the isomerization of linoleic acid was to provide a basis for our daily cooking with limits on the temperatures of cooking oils.

\section{Materials and methods}

\section{Materials}

Trilinolein of chemically pure grade was purchased from Tokyo Chemical Industry. A 37-component fatty acid methyl ester (FAME) mix was obtained from Supelco, USA. The cis/trans linoleic acid methyl ester standards, including cis-linoleic acid methyl ester (C18:2-9c12c) and trans-linoleic acid isomer methyl esters (C18:2-9c12t, C18:2-9c12t, C18:2-9t12t) were purchased from Sigma-Aldrich (Bellefonte, PA, USA). Hexanal, trans,trans2,4-decadienal, trans-2-decenal, trans-2-nonenal and trans-2hexenal, were obtained from Sigma-Aldrich. All chemicals used were of chromatographic grade (Merck, Darmstadt, Germany).

\section{Heating procedures}

About $1 \mathrm{~g}$ of trilinolein was transferred to a $10 \mathrm{~mL}$ glass tube, and incubated in a methyl silicon oil bath for $5 \mathrm{~h}$ at 140, 160, $180,200,220{ }^{\circ} \mathrm{C}$, respectively. The accuracy of the temperature control for the oil heating was $\pm 1{ }^{\circ} \mathrm{C}$. The heated samples were cooled to room temperature, and then sealed under nitrogen and stored at $-20{ }^{\circ} \mathrm{C}$ before the chemical analysis.

\section{Differential scanning calorimetry (DSC) analysis of trilinolein}

The unheated pure trilinolein (about 3-5 mg) was coated evenly over the bottom of a crucible and then sealed. Samples of pure trilinolein were scanned at $5{ }^{\circ} \mathrm{C} \min ^{-1}$ to $250{ }^{\circ} \mathrm{C}$. All the measurements were performed in triplicate. A computer collected the experimental data and drew the DSC thermogram.

\section{Preparation of FAMEs}

The heat-treated trilinolein samples were derivatized into their methyl esters according to a developed method described in a previous report..$^{23}$ First, $20 \mathrm{mg}$ of trilinolein was weighed in a stoppered glass tube, then $4 \mathrm{~mL}$ of $2 \%$ sulfuric acid/methanol was added into the vial, and the stoppered glass tube was placed in a water bath at $80{ }^{\circ} \mathrm{C}$ for $2 \mathrm{~h}$. Soon afterwards $2 \mathrm{~mL}$ of deionized water and $2 \mathrm{~mL}$ of $n$-hexane were added to the cooled glass tube. The solution was stirred for $2 \mathrm{~min}$, and the supernatant layer was transferred to a new glass tube with $1 \mathrm{~mL}$ of $2 \%$ $\mathrm{KOH}$ solution. The mixture was shaken for $1 \mathrm{~min}$, and the $n$ hexane phase was removed. Approximately $1 \mathrm{~g}$ of anhydrous sodium sulfate was added before its contents were analyzed by GC.

\section{Determination of fatty acids by GC}

Analysis of fatty acid methyl esters was conducted using a Shimadzu (Tokyo, Japan) GC-2010 instrument equipped with a fused-silica capillary column HP-88 $(100 \mathrm{~m} \times 0.25 \mathrm{~mm} \times 0.20$ $\mu \mathrm{m})$ and a flame ionization detector (FID) with nitrogen as the carrier gas at a column pressure of $169 \mathrm{kPa}$, and a split ratio of $100: 1$. The injection and detection were performed at 225 and $230{ }^{\circ} \mathrm{C}$, respectively. The program was set at an initial temperature of $60{ }^{\circ} \mathrm{C}$ for $5 \mathrm{~min}$ before it was increased to $160{ }^{\circ} \mathrm{C}$ by a temperature gradient of $25{ }^{\circ} \mathrm{C} \mathrm{min}^{-1}$ and held for $5 \mathrm{~min}$. Finally, the temperature was increased to $225{ }^{\circ} \mathrm{C}$ at a rate of $2{ }^{\circ} \mathrm{C} \mathrm{min}{ }^{-1}$ and remained at $225{ }^{\circ} \mathrm{C}$ for $14.5 \mathrm{~min} .{ }^{24}$ Fatty acid methyl esters were analyzed by comparing the retention times with the standards of cis and trans linoleic acid methyl ester.

\section{GC-calculation}

The amount of each fatty acid (FA) (C18:2-9c12t, C18:2-9t12c, C18:2-9t12t, C18:2-9c12c) was detected in the test sample by GC-FID and calculated according to eqn (1).

$$
W_{\mathrm{i}}=\frac{\left(A_{\mathrm{i}}-B_{\mathrm{i}}\right) \times 1.0046}{K_{\mathrm{i}}} \times\left(\frac{\mathrm{MFA}_{\mathrm{i}}}{\mathrm{MFAME}_{\mathrm{i}}}\right) \times\left(\frac{V_{\mathrm{k}}}{M_{\mathrm{i}}}\right)
$$

where $W_{\mathrm{i}}$ is the weight of fatty acid in the samples, $A_{\mathrm{i}}$ is the peak area of the individual $\mathrm{FAME}_{\mathrm{i}}$ in the sample, $B_{\mathrm{i}}$ is the intercept on the linear curve, $K_{\mathrm{i}}$ is the correlation coefficient of the linear curve, 1.0046 is the conversion coefficient between trilinolein and FAME C18:2, MFA is the molecular weight of $\mathrm{FA}_{i}$, and MFAME $_{\mathrm{i}}$ is the molecular weight of FAME,$V_{\mathrm{k}}$ is the volume of the solvent when the sample is dissolved, and $M_{\mathrm{i}}$ is the quantity of trilinolein in the sample. 


\section{Quantum chemistry calculation}

All calculations were carried out using the Gaussian $09 \mathrm{~W}$ software provided by the Laboratory of Food Quality and Safety, Tianjin University of Science and Technology. ${ }^{25}$ The three parameters of Beck and the nonlocal correlation function of Lee-Yang-Parr (LYP) were used to calculate the geometries, transition states and geometries of the ground state at the 6$31 \mathrm{G}^{*}$ level. All the transition states and the ratios of the intermediates were obtained from the IRCs.

\section{HPLC analysis}

The carbonyl compounds of the heat-inducing products were determined using an HPLC system (Shimadzu, Tokyo, Japan) equipped with diode-array detection, and C18-column TSK gel ODS-80Ts $(250 \mathrm{~mm} \times 4.6 \mathrm{~mm}, 5 \mu \mathrm{m})$. Separation was achieved at a thermostat setting of $50{ }^{\circ} \mathrm{C}$ using a flow rate of 1.3 $\mathrm{mL} \min ^{-1}$. The mobile phase was acetonitrile and water, 75:25 (v/v). Monitoring was carried out at $365 \mathrm{~nm}$ and the relative chromatogram areas and the absolute content for the major carbonyl compounds were calculated.

\section{Statistical analysis}

All determinations were performed in duplicate. The data was presented as means \pm SD (standard deviation). The data was analyzed using SPSS (version 16.0, SPSS Inc., Chicago, IL, USA). The difference was significant at the level of $p<0.05$.

\section{Results and discussion}

\section{Thermal analysis of trilinolein}

As shown in Fig. 1, there is a significant endothermic peak flow signal recorded at a calorimetric temperature from $139.85^{\circ} \mathrm{C}$ to 204.76 ${ }^{\circ} \mathrm{C}$ in the differential thermal scanning analysis. The highest heat-flow peak appeared at $183.69^{\circ} \mathrm{C}$, and the enthalpy change reached $21.79 \mathrm{~J} \mathrm{~g}^{-1}$. The presence of this peak was

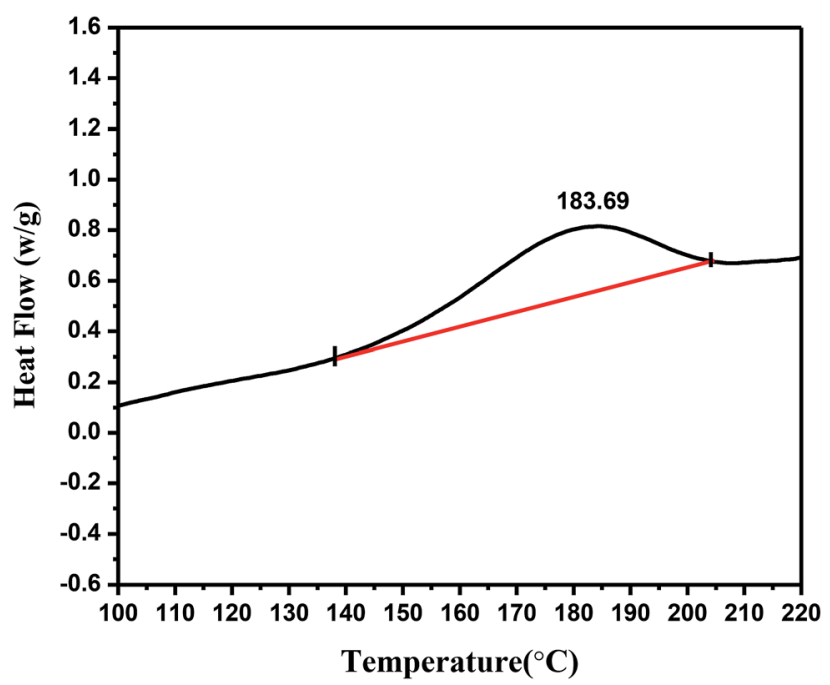

Fig. 1 DSC thermogram showing the thermally induced point of isomerization of trilinolein. attributed to the occurrence of the isomerization of linoleic acid in the case of heat induction and the breakage of chemical bonds accompanying heat release. This information provides a basis for studying the temperature range of the linoleic acid isomerization and thermal cracking reaction.

\section{Isomer analyses of C18:2 by GC}

The isomerization rate of the double bond in trilinolein was monitored by measuring the accumulation of trans isomers and residual cis isomers. The GC results of the four isomer FAMEs of heated trilinolein are shown in Fig. 2. No trans isomer was detected in the normal state at $120^{\circ} \mathrm{C}$. It can be observed that the total content of $c$ is isomers (12c9c) decreased almost linearly with heating temperature, and the trans contents of $12 \mathrm{c} 9 \mathrm{t}, 9 \mathrm{t} 12 \mathrm{c}$ and $9 \mathrm{t} 12 \mathrm{t}$ isomers increased with an increase in the heating temperature. As a result, there was a $25 \%$ decrease in the concentration of $9 \mathrm{c} 12 \mathrm{c}$, when it was heated from $140{ }^{\circ} \mathrm{C}$ to $220^{\circ} \mathrm{C}$ for $5 \mathrm{~h}$. The remaining amount of $9 \mathrm{c} 12 \mathrm{c}$ was significantly reduced at $180{ }^{\circ} \mathrm{C}$, reaching a minimum at $220{ }^{\circ} \mathrm{C}$. It can be observed that the mono-trans isomer was preferentially detected and the 9c12t and 9t12c levels were positively correlated with the heating temperature. In this study, 9t12t was not found at $140{ }^{\circ} \mathrm{C}$ or $160{ }^{\circ} \mathrm{C}$ but was only detected at $180{ }^{\circ} \mathrm{C}$ in the oxidized trilinolein. This isomerization temperature was consistent with the DSC analysis. Some authors have pointed out that the temperature for the isomerization of linoleic acid is $180{ }^{\circ} \mathrm{C}$ in heated soybean oil, which also shows that the reaction system does not affect the isomerization temperature. ${ }^{21}$

As shown in Fig. 2, the C18:2-9c12t and C18:2-9t12c, are richest in the concentration of components in the trans isomers (9c12t, 9t12c). Since the mono-trans isomer is easier to detect than the trans-trans isomer, we can guess that there are two paths in the process by which 9c12c linoleic acid is completely converted to $9 \mathrm{t} 12 \mathrm{t}$ in preference to the forms 9c12t or 9t12c. There was a low proportion of $9 \mathrm{t} 12 \mathrm{t}$ in the sample, so $9 \mathrm{c} 12 \mathrm{t}$ and

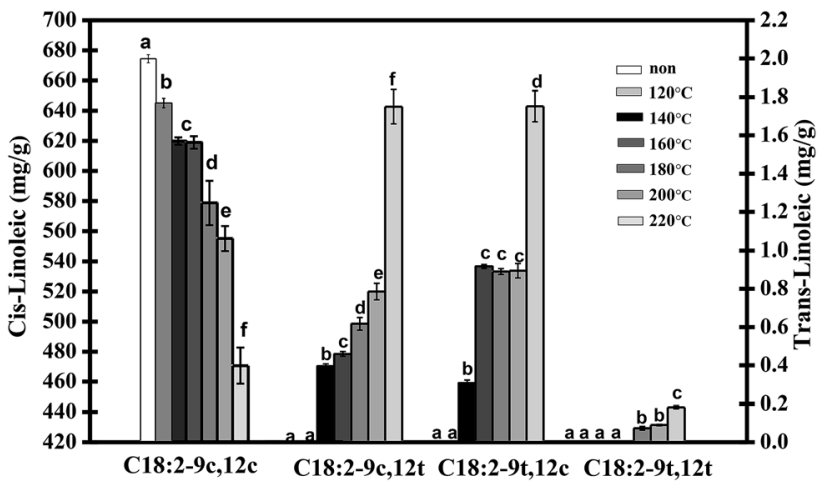

Fig. 2 The amount of cis and trans isomers in trilinolein when $1 \mathrm{~g}$ of each trilinolein was incubated for $5 \mathrm{~h}$ at $120^{\circ} \mathrm{C}, 140^{\circ} \mathrm{C}, 160^{\circ} \mathrm{C}, 180^{\circ} \mathrm{C}$, $200^{\circ} \mathrm{C}, 220^{\circ} \mathrm{C}$, respectively. The absolute amount of each isomer was calculated from the peak intensity of an external standard (37 Comp.) FAME. The values represent the means \pm three times SD. The values at temperature points not sharing common letters of the alphabet are significantly different $(P<0.05)$. The linoleic acid measured was normalized to $100 \%$. 
9t12c were the major trans isomers. Linoleic acid (12c9c) was isomerized fast with the rise in temperature, so it can be reasoned that the quantity of trans isomers formed was closely related to the temperature. The amount of isomerization products at $160{ }^{\circ} \mathrm{C}\left(1.549 \mathrm{mg} \mathrm{g}^{-1}\right)$ was 1.98 times higher than that at $140{ }^{\circ} \mathrm{C}\left(0.782 \mathrm{mg} \mathrm{g}^{-1}\right)$. This can cause intensive isomerization of polyunsaturated fatty acid at frying temperatures above $200{ }^{\circ} \mathrm{C}$, and the quantity of the product was 2.09 times higher at $220{ }^{\circ} \mathrm{C}\left(3.971 \mathrm{mg} \mathrm{g}^{-1}\right)$ than that at $200{ }^{\circ} \mathrm{C}$. These results were consistent with previous observations by Chen et al. $^{26}$ Choe and $\mathrm{Min}^{27}$ reported that a number of chemical reactions, such as oxidation, isomerization, and polymerization, occurred in heating oil. Therefore, the heating temperature of an oil rich in linoleic acid should be controlled to no more than $140{ }^{\circ} \mathrm{C}$ to avoid the risk of ingestion of trans fatty acids in the daily diet.

\section{Quantum chemistry calculation analysis of isomerization}

Information about the ground states of the isomers and the double bond isomerization of linoleic acid was obtained by performing DFT calculations at the B3LYP/6-31G* level. The geometries of the optimized reactants, intermediates, transition states and products of C18:2 in their ground states are shown in Table 1. The optimized dihedral angles C8-C9-C10-C11 $\left(\theta^{1}\right)$ and $\mathrm{C} 11-\mathrm{C} 12-\mathrm{C} 13-\mathrm{C} 14\left(\theta^{2}\right)$ for the isomer $\mathrm{C} 18: 2-9 \mathrm{c} 12 \mathrm{c}$ were $-0.272^{\circ}$ and $0.850^{\circ}$, respectively. However, cis carbon bonds $\mathrm{C} 9=\mathrm{C} 10$ and $\mathrm{C} 12=\mathrm{C} 13$ preferentially formed the cis,trans isomer (C18:2-12c9t) or trans,cis isomer (C18:2-9t12t), and these dihedral angles were $-0.106^{\circ}, 179.805^{\circ}$ and $179.564^{\circ}$, $-0.031^{\circ}$. The trans,trans isomer (C18:2-9t12t) was formed and the angles changed to $179.789^{\circ}$ and $-178.774^{\circ}$. The relative deviation of the two dihedral angles from the ideal values (cis, $0^{\circ}$; trans, $\left.180^{\circ}\right)$ is in close proximity $\left(<1^{\circ}\right)$. The difference between the dihedral angle and the ideal value was very small, which showed the true reliability of the simulation results. We should notice that in each isomer the lengths of the cis $\mathrm{C}==\mathrm{C}$ (1.345-1.347 $\mathrm{A})$ are more than the trans $\mathrm{C}==\mathrm{C}(1.342-1.343 \AA)$.
These trans double bonds are shorter than the cis double bonds, so the trans isomer is more stable than the cis isomer (Table 1).

The conversion of high-energy linoleic acid (C18:2-9c12c) to low-energy molecules (C18:2-9t12t) is a spontaneous process. However, the reaction process is not easy to carry out at room temperature or without a catalyst. If the reaction is to take place smoothly, it is necessary to provide the activation energy required for the reaction to cross the higher energy barrier. Tsuzuki ${ }^{28}$ reported that the trans double bond exhibited higher thermodynamic stability than the cis double bond in oleic acid. In this study the energy difference was calculated between the cis and trans structures in linoleic acid which was equal to $6.2 \mathrm{~kJ} \mathrm{~mol}^{-1}$. And the energy difference between cis and trans oleic acid was equal to $7.6 \mathrm{KJ} \mathrm{mol}^{-1}$, which was much higher than that of linoleic acid..$^{21}$ Frankel $^{29}$ reported that the linoleic acid ester reactivity was 40 times higher than that of oleate, but the rate of linoleic acid isomerization and oxidation cracking was faster than that of oleic acid. Our laboratory also proved this theory, and the temperatures of isomerization of linoleic acid and oleic acid were $140{ }^{\circ} \mathrm{C}$ and $150{ }^{\circ} \mathrm{C}$, respectively. The conclusion is consistent with our findings. This paper demonstrates that the temperature of isomerization of linoleic acid is $140{ }^{\circ} \mathrm{C}$, and the temperature for oleic acid is $150{ }^{\circ} \mathrm{C}$, as was shown by our laboratory previously. ${ }^{22}$ This indicates that linoleic acid is more prone to isomerization than oleic acid under heat treatment.

The intramolecular proton transfer from the ground state to the excited state under a high temperature was hypothesized. Thus, the cis double bonds of unsaturated fatty acids may undergo a hydrogen abstraction such that the external condition causes the molecule to be in the excited state, and the proton obtains enough energy to transfer within the molecule (two alternative rotational isomerization schemes of the C18:2 transformation are displayed in Fig. S1 in the ESI $\dagger$ ) and the geometric configuration energy variation is shown in Fig. 3(A1 and B1). The energy level diagram for the isomerization indicated that in the obtained minimum energy scheme the C18:2-

Table 1 Characteristics of the cis and trans isomers in the ground state, transition states (ts), and intermediates (im) of A and B schemes, as calculated by the DFT method

\begin{tabular}{|c|c|c|c|c|c|c|c|c|c|c|c|c|c|}
\hline \multirow{2}{*}{$\begin{array}{l}\text { Species, } \\
\text { A scheme } \\
(\mathrm{C} 18: 2)\end{array}$} & \multicolumn{4}{|c|}{ Bond length $(\AA)$} & \multicolumn{2}{|c|}{ Dihedral angle $\left(^{\circ}\right)$} & \multirow{2}{*}{$\begin{array}{l}\begin{array}{l}\text { Species, B } \\
\text { scheme }\end{array} \\
(\mathrm{C} 18: 2)\end{array}$} & \multicolumn{4}{|c|}{ Bond length $(\AA)$} & \multicolumn{2}{|c|}{ Dihedral angle $\left(^{\circ}\right)$} \\
\hline & $\mathrm{C} 9=\mathrm{C} 10$ & C10-C11 & $\mathrm{C} 11-\mathrm{C} 12$ & $\mathrm{C} 12=\mathrm{C} 13$ & $\theta_{1}^{a}$ & $\theta_{2}{ }^{b}$ & & $\mathrm{C} 9=\mathrm{C} 10$ & C10-C11 & C11-C12 & $\mathrm{C} 12=\mathrm{C} 13$ & $\theta_{1}^{a}$ & $\theta_{2}{ }^{b}$ \\
\hline $9 c, 12 c$ & 1.346 & 1.517 & 1.515 & 1.346 & -0.272 & 0.850 & $9 c, 12 c$ & 1.346 & 1.517 & 1.515 & 1.346 & -0.272 & 0.850 \\
\hline tsa1 & 1.346 & 1.512 & 1.516 & 1.418 & 0.190 & -8.322 & tsb1 & 1.420 & 1.518 & 1.512 & 1.346 & -8.746 & 0.500 \\
\hline ima1 & 1.345 & 1.509 & 1.491 & 1.495 & 0.163 & -8.179 & imb1 & 1.494 & 1.492 & 1.511 & 1.345 & -16.123 & 0.859 \\
\hline $9 c, 12 t$ & 1.346 & 1.515 & 1.516 & 1.342 & -0.106 & 179.805 & $9 \mathrm{t}, 12 \mathrm{c}$ & 1.343 & 1.515 & 1.516 & 1.346 & 179.564 & -0.031 \\
\hline tsa3 & 1.419 & 1.521 & 1.515 & 1.343 & 10.825 & 179.490 & tsb3 & 1.343 & 1.510 & 1.516 & 1.418 & 179.835 & -8.179 \\
\hline ima3 & 1.419 & 1.522 & 1.511 & 1.342 & 8.964 & -179.908 & imb3 & 1.342 & 1.511 & 1.494 & 1.492 & -179.769 & -30.875 \\
\hline ima4 & 1.495 & 1.489 & 1.507 & 1.342 & -157.516 & -179.868 & imb4 & 1.342 & 1.514 & 1.487 & 1.485 & 179.761 & -154.259 \\
\hline tsa4 & 1.495 & 1.489 & 1.507 & 1.342 & 96.979 & -179.909 & $\mathrm{tsb} 4$ & 1.343 & 1.518 & 1.520 & 1.409 & -179.704 & 174.079 \\
\hline $9 t, 12 t$ & 1.343 & 1.518 & 1.510 & 1.343 & 179.789 & -178.774 & $9 t, 12 t$ & 1.343 & 1.518 & 1.510 & 1.343 & 179.789 & -178.774 \\
\hline
\end{tabular}

${ }^{a}$ Dihedral angle of C8-C9-C10-C11. ${ }^{b}$ Dihedral angle of C11-C12-C13-C14. 


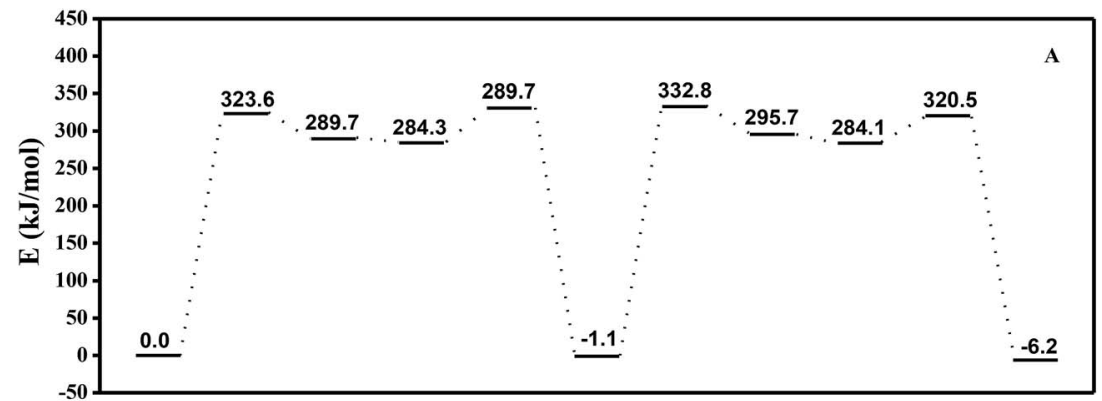

Reaction coordinate

(A1)

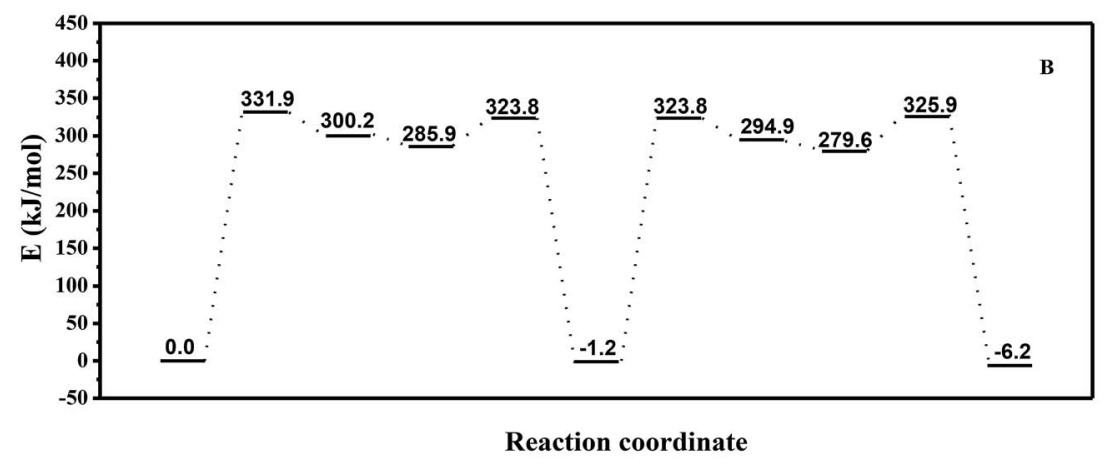

(B1)

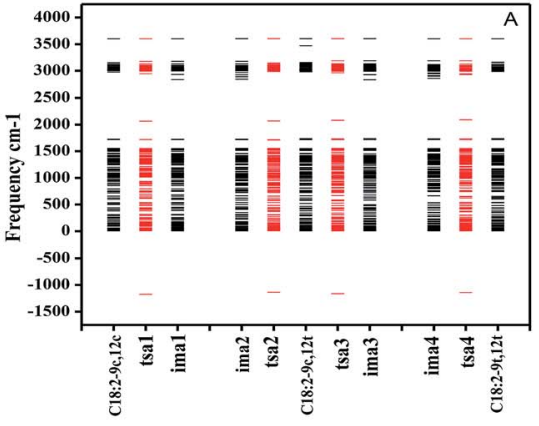

(A2)

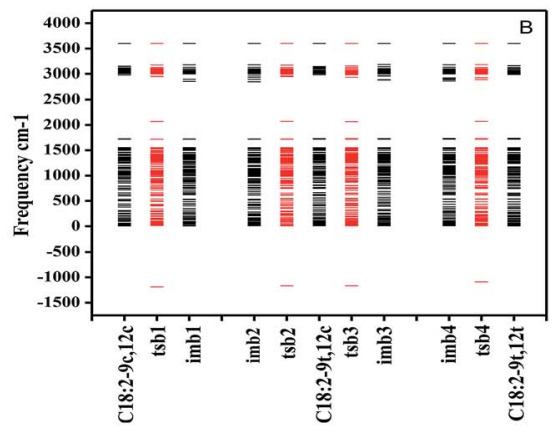

(B2)

Fig. 3 Energy level diagram for the isomerization reaction schemes (A1) and (B1). And frequencies for the reactant C18:2-9c12c, transition states (ts), intermediates (im), and the product C18:2-9t12t ((A2) and (B2) schemes). As observed, the transition states have only one imaginary frequency.

$9 \mathrm{c} 12 \mathrm{c}$ crosses the energy barrier to reach the transition state to produce intermediates with a free radical containing a cis double bond. To rotate the cis $\mathrm{C}=\mathrm{C}$ double bond, a $\pi$ bond is broken in the transition state. Thermal induction provided a higher activation energy and allowed intermediates to cross the energy barrier to produce fewer energy products, and the cis double bond was rotated to a trans double bond during this progress. There were two schemes in this study. The A scheme showed an isomerization process of 9c12c $\rightarrow$ tsa1 $\rightarrow$ ima1, ima $2 \rightarrow$ tsa $2 \rightarrow$ 9c12t $\rightarrow$ tsa3 $\rightarrow$ ima3, ima $4 \rightarrow$ tsa $4 \rightarrow$ 9t12t and the B scheme was $9 \mathrm{c} 12 \mathrm{c} \rightarrow \mathrm{tsb} 1 \rightarrow \mathrm{imb} 1, \mathrm{imb} 2 \rightarrow \mathrm{tsb} 2 \rightarrow$ 9t12c $\rightarrow$ tsb3 $\rightarrow$ imb3, imb4 $\rightarrow$ tsb4 $\rightarrow$ 9t12t via four transition states (ts) and four intermediates (im) in each scheme. There are four peaks and two valleys (two intermediates are in the same valley) which represent transition states and intermediates, respectively (see Fig. S2 in the ESI $\dagger$ ). Vibrational frequency calculations were carried out using DFT methods to verify each transition state. Only one imaginary frequency characterizes the transition states and the activation energy $(\Delta E)$ was different between the zero-point energy corrections of the cis isomer and that of the transition states (ts) or intermediates (im). Only one imaginary (negative) frequency characterized the transition states, which was used to verify the transition states, as shown in Fig. 3(A2 and B2). It also displays other characteristics, such as the bond length and the dihedral angle concerned, as collected in Table 1.
The relative energy values were calculated for the formation of the 9c12t and 9t12c isomers (Fig. 3A1 and B1). The relative energy of formation of the $9 \mathrm{c} 12 \mathrm{t}$ isomer was $1.1 \mathrm{~kJ} \mathrm{~mol}^{-1}$, which was nearly identical to that of the $9 \mathrm{t} 12 \mathrm{c}$ isomer $\left(1.2 \mathrm{~kJ} \mathrm{~mol}^{-1}\right)$. Guo et $a .^{30}$ also reported that the energy of formation for the 9c12t and 9t12c isomers were $116.28 \mathrm{~kJ} \mathrm{~mol}^{-1}$ and $114.48 \mathrm{~kJ} \mathrm{~mol}^{-1}$. These two values are basically equal, which is consistent with our results. This provides a further rationale for the same ratio of $9 \mathrm{c} 12 \mathrm{t}$ and $9 \mathrm{t} 12 \mathrm{c}$ isoforms being formed upon heating of trilinolein. However, the concentration of 9c12t was slightly higher than that of $9 \mathrm{t} 12 \mathrm{c}$ at $140{ }^{\circ} \mathrm{C}$; the amount of $9 \mathrm{t} 12 \mathrm{c}$ became gradually higher than that of $9 \mathrm{c} 12 \mathrm{t}$ in the samples with an increased temperature. In Fig. 3(A and B), the energy barrier of the transition state of tsa1 $\left(323.6 \mathrm{~kJ} \mathrm{~mol}^{-1}\right)$ was $8.3 \mathrm{~kJ} \mathrm{~mol}^{-1}$ lower than that of tsb1 $\left(331.9 \mathrm{~kJ} \mathrm{~mol}^{-1}\right)$, and that of tsa3 (332.8 $\mathrm{kJ} \mathrm{mol}^{-1}$ ) was $9.0 \mathrm{~kJ} \mathrm{~mol}^{-1}$ higher than that of tsb3 $\left(323.8 \mathrm{~kJ} \mathrm{~mol}^{-1}\right)$. Therefore, it can be deduced that it was easier for $9 \mathrm{c} 12 \mathrm{c}$ to form $9 \mathrm{c} 12 \mathrm{t}$ than to form $9 \mathrm{t} 12 \mathrm{c}$ since this process first reached the 9c12t energy barrier, so that the A path was followed. As the temperature increased, the energy barrier of tsa3 (332.8 $\left.\mathrm{kJ} \mathrm{mol}^{-1}\right)$ was higher than that of tsb3 $\left(323.8 \mathrm{~kJ} \mathrm{~mol}^{-1}\right)$, so the B scheme was easier than the A scheme according to the activation energy for the isomerization. Thus, this explains why there was more C18:2-9t12c. Therefore, this result suggests that activation energy is important for the isomerization rate, and the reason that there is more $9 \mathrm{c} 12 \mathrm{t}$ than 
9t12c isomer at $140{ }^{\circ} \mathrm{C}$ can be explained with the results in Fig. 2.

In the A scheme, the force between C12-H12 decreased under high temperature, so that hydrogen atom H12 was probably transferred to $\mathrm{C} 13$, which increased the bond length of $\mathrm{C} 12-\mathrm{C} 13(1.346 \rightarrow 1.418 \rightarrow 1.495 \AA)$, as given in Table 1. A high energy barrier (323.6 $\mathrm{kJ} \mathrm{mol}^{-1}$ ) must be overcome from C18:29c12c to ima1, as shown in Fig. 3(A1 and B1). The energy difference between ima1 (imb1) and ima2 (imb2) was $5.4 \mathrm{~kJ} \mathrm{~mol}^{-1}$ : the small energy difference between the two isomers with a double bond turning into a single bond and consequently the possible rotation of this bond. When the proton transfer was finished, the $\mathrm{C} 12-\mathrm{C} 13$ double bond was reestablished, which led to the formation of C18:2-9c12t. C18:2$9 \mathrm{c} 12 \mathrm{t}$ accumulated to a certain degree with the rise in temperature, and the isomerization of the C12-C13 double bond was activated. Therefore, the C18:2-9t12t molecule with two trans double bonds was formed. As the isomerization process of the C9-C10 double bond was similar to that of C12-C13, this was why the B scheme of isomerization was almost similar to the A scheme. This study has concluded that the conversion of cis linoleic acid to the trans structure was the result of the transfer of a proton. We further detected the secondary products to investigate the mechanism of high-temperature heat-induced linoleic acid.

\section{Carbonyl compounds were detected by HPLC}

Some of the decomposition products during thermal induction in trilinolein, including mostly saturated and unsaturated aldehydes and shorter fatty acids have been reported previously. ${ }^{31,32}$ Aldehydes constitute the most numerous group of carbonyl derivatives formed in any oil oxidation process. Frankel $^{29}$ reported that the significant compounds responsible were trans-2-hexenal, hexanal, trans-2-nonenal. Trans,trans-2,4decadienal, trans-2-decenal as calculated from their concentrations. The 2,4-decadienal and 2-decenal were detected in soybean oil by continuous heating. ${ }^{33}$

The five major aldehydes were quantitatively analyzed by HPLC in this study (Fig. 4). Hexanal was the main component and occupied around $50.35 \%$ of the total carbonyl derivatives with the highest proportions, followed by trans,trans-2,4-decadienal and trans-2-decenal account for $31.65 \%$ and $13.55 \%$ in the samples. The total amount of trans-2-hexenal was the lowest, accounting for only $0.17 \%$ in trilinolein at $140{ }^{\circ} \mathrm{C}$. However, as the oxidation level increased, the concentration of aldehydes decreased, and the total amount of the five aldehydes was reduced from $4.882 \mathrm{mg} \mathrm{g}^{-1}$ to $0.570 \mathrm{mg} \mathrm{g}^{-1}$ when the temperature was raised to $140{ }^{\circ} \mathrm{C}$ and $220{ }^{\circ} \mathrm{C}$ for $5 \mathrm{~h}$, respectively. It should be noticed that the concentrations of hexanal, trans,trans-2,4-decadienal and trans-2-nonenal decreased (Fig. 4). This can be attributed to the open receptacles, so some of the volatile substances reaching their boiling point presented greater volatilization than production or further decomposition into other small molecules which volatilized into the air subsequently. However, the concentrations of trans-2-decenal and trans-2-hexenal were increased first and then decreased in

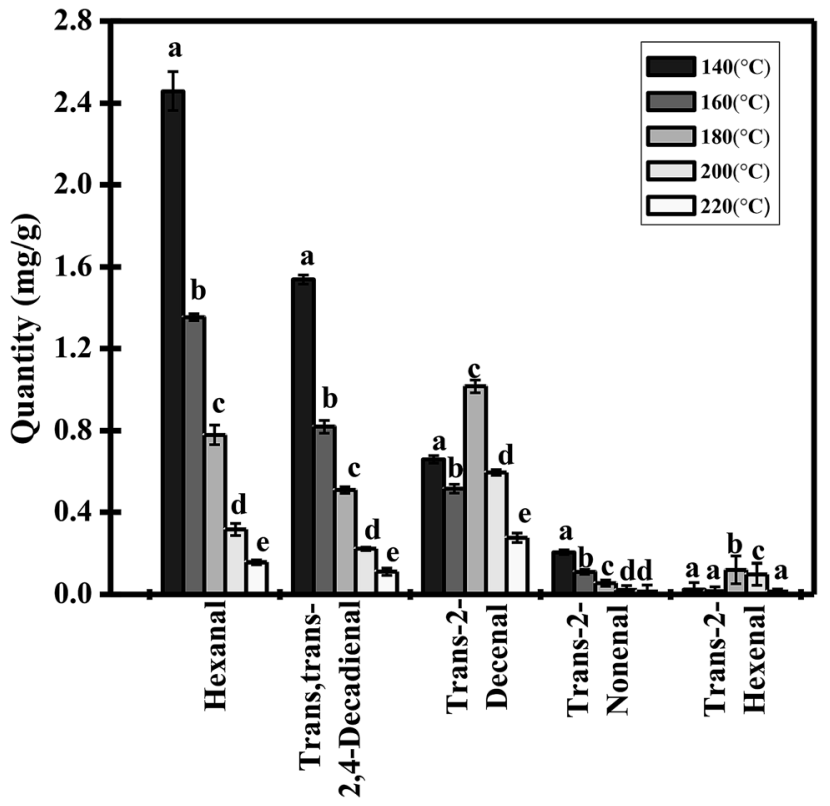

Fig. 4 Concentration profiles of carbonyl compounds in heated trilinolein. The values represent the means \pm three times SD.

the thermally oxidized trilinolein. These observations suggest that it is possible to explain the formation mechanism of the two aldehydes from an energy point of view.

\section{Quantum chemistry calculation analysis of oxidation mechanism}

It is generally believed that the oxidation of fatty acids is a free radical chain reaction, in which a carbon that requires the least energy for removal of a hydrogen atom is attacked by triplet oxygen, forming hydrogen radicals and lipid peroxyl radicals. ${ }^{34}$ Because radicals are thermodynamically unstable, they are immediately converted into stable compounds. The bond dissociation energy is the energy of a bond in a molecule or the energy consumed or released, which affects the stability of the bond. The BDEs of C8-H8, C9-H9, C10-H10, C11-H11, C12H12, C13-H13 and C14-H14 are shown in Table 2. The energy of the carbon-hydrogen bond on $\mathrm{C} 8$ or $\mathrm{C} 14$ was about $313.8 \mathrm{~kJ} \mathrm{~mol}^{-1}$ and the energy of the carbon-hydrogen bond on the saturated carbon with a single bond next to it was about $418.4 \mathrm{~kJ} \mathrm{~mol}^{-1}$. And the energy required to break away was about $209.2 \mathrm{~kJ} \mathrm{~mol}^{-1}$ for the carbon-hydrogen bond on $\mathrm{C}_{11 .}{ }^{27}$ The weakest carbon-hydrogen bond of linoleic acid was the diallyl hydrogen at C11, so that C11-H11 will be broken and then the hydrogen atom (H11) attached to it will be the first to be removed to form radicals. The double bonds at C9 and C12 decrease the carbon-hydrogen bond at C11 by withdrawing electrons. Unsaturated chain hydrocarbons may have two types of hydrogen bonds from $\mathrm{C}\left(\mathrm{sp}^{2}\right)-\mathrm{H}$ and $\mathrm{C}(\mathrm{sp})-\mathrm{H}$, resulting in super conjugation and spin-delocalization effects, which affect free radical stability and the bond dissociation enthalpy of the carbon-hydrogen bond. Since the electronegativity of each atom is different, the electron cloud shifts and is transmitted 
Table 2 The $\mathrm{C}-\mathrm{H}$ and $\mathrm{C}-\mathrm{C}$ bond dissociation energy (BDE kJ mol ${ }^{-1}$ ) of $\mathrm{C} 18: 2-9 \mathrm{c} 12 ; \mathrm{C} 18: 2-9 \mathrm{c} 12 \mathrm{t}$; $\mathrm{C} 18: 2-9 \mathrm{t} 12 \mathrm{c}$; $\mathrm{C} 18: 2-9 \mathrm{t} 12 \mathrm{t}$ in the ground electronic state, as calculated by the B3LYP/6-31*G method

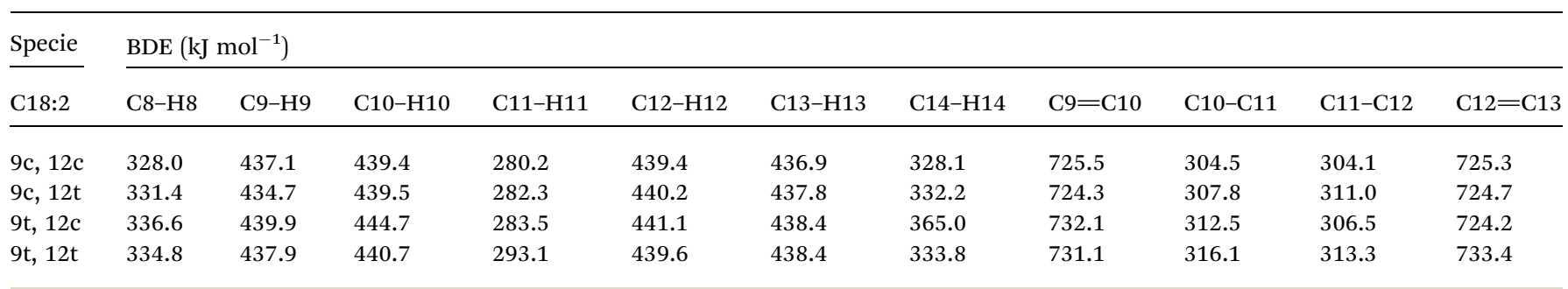

along the $\sigma$ bond, so the effect affects the direction of formation of the bonding. ${ }^{31}$

Reasonable speculation about the mechanism of formation of trilinolein into carbonyl compounds was in accordance with the $\mathrm{BDE}$ values of the $\mathrm{C}-\mathrm{H}$ and $\mathrm{C}=\mathrm{C}$ bonds in linoleic acid (Table 2). The bisallylic hydrogen atom of trilinolein tends to form a radical intermediate product by thermal oxidation. Subsequently, hydroperoxide was formed by the reaction with the ground state oxygen. Aldehydes and short chain fatty acids were rapidly formed by heating because of its extreme instability. In this study, when C18:2-9c12t formed a hydroperoxide, the hydroxyl group was formed on $\mathrm{C} 12$ (C12-H12 was equal to $440.2 \mathrm{~kJ} \mathrm{~mol}^{-1}$, higher than for the other $\mathrm{C}-\mathrm{H}$ bonds) and simultaneous migration of the intramolecular $\mathrm{C} 12=\mathrm{C} 13$ double bond to $\mathrm{C} 13=\mathrm{C} 14$. The activated hydroperoxide of a molecule possesses stronger thermodynamic instability, so that it can easily be cleaved into a secondary product (C18:2$9 \mathrm{c} 12 \mathrm{t}$ degradation scheme of reactant), transition states, and the product (aldehydes and olefinic alcohol, see Fig. S3 in the ESI $\dagger$ ). The reaction energy from C18:2-9c12t to low molecular product (aldehyde and enol) was $98.9 \mathrm{~kJ} \mathrm{~mol}^{-1}$ when the sample was heated (for energy curves of the hydroperoxide degradation reaction scheme, see Fig. S4 in the ESI $\dagger$ ). This energy is low, so the oxidative degradation reaction is easier to carry out. This deduction is consistent with the mechanism of lipid oxidation in Frankel. ${ }^{29}$

The bond dissociation energy of C10-C11, C11-C12 is lower than that of $\mathrm{C} 9=\mathrm{C} 10, \mathrm{C} 12=\mathrm{C} 13$, and the energy differences are 420.1-429.3 $\mathrm{kJ} \mathrm{mol}^{-1}$ (Table 2). Comparison of the four linoleic acid isomers in $\mathrm{C} 9=\mathrm{C} 10, \mathrm{C} 12=\mathrm{C} 13$ found that the trans double bond BDE was higher than that of the cis double bond (0.5$9.2 \mathrm{~kJ} \mathrm{~mol}^{-1}$ ), indicating that the trans double bond is more stable than the cis double bond. We can speculate that most of the cracking products come from the thermal oxidation of 9c12c, 9c12t or 9t12c but not 9t12t. Quantum chemical calculations explain the formation of these pyrolysis products from the energy point of view and provide a theoretical basis for the oxidation of linoleic acid.

\section{Conclusion}

The results showed that with thermal induction of the C18:2$9 \mathrm{c} 12 \mathrm{c}$ form of triliolein the fatty acid moieties undergo an isomerization reaction into their positional isomers and then degrade into aldehydes. This causes a reduced edible value and affects the oil safety. Under high-temperature induction conditions, C18:2-9c12c first forms mono-trans linoleic acid, then C18:2-9t12t. The concentration distribution of trans structures (9c12t, 9t12c, 9t12t) in the result was explained by the DFT method from the point of view of quantum chemistry, and offered a reasonable interpretation of the process of conversion of the cis into the trans form from an energy point of view. The energy barrier between the cis and the trans forms differs during the reaction, which indicates that the formation of trans linoleic acid under high temperature conditions has certain advantages. We should focus more on two aspects of information about the isomerization and oxidation mechanism of triliolein. On the one hand, oxidative degradation with unpleasant odors has a serious impact on the practicality of the oil, so controlling the temperature correctly is essential to avoid the formation of large quantities of pyrolysis products. On the other hand, intake of trans fatty acids affects human health. Temperature is key to isomerization reactions, and controlling daily cooking temperature is the most effective measure to avoid ingestion of trans fatty acids.

\section{Conflicts of interest}

There are no conflicts to declare.

\section{Acknowledgements}

This work was supported by the Ministry of Science and Technology of the People's Republic of China (Project No. 2016YFD0401404) the Foundation (No. gxb201805) of Demonstration Center of Food Quality and Safety Testing Technology, Tianjin University of Science and Technology, P. R. China and the Project program of Key Laboratory of Food Nutrition and Safety, Ministry of Education, China (No. 2018008) and Innovation Fund of Tianjin University of Science and Technology for Young Teachers (2017LG01).

\section{References}

1 Q. Guo, F. Wang, F. He, Y.-m. Ha, Q.-p. Li, J. Jin and Z.-x. Deng, J. Food Sci. Technol., 2015, 53, 1487-1495.

2 L. Xu, X. Yu, L. Lei and Z. Rui, Food Chem., 2016, 202, 229.

3 P. Nestel, Clin. Ther., 2014, 36, 315-321.

4 E. Koh and J. Surh, Food Chem., 2015, 174, 467-472. 
5 Y. Hirata, M. Takahashi, Y. Kudoh, K. Kano, H. Kawana, K. Makide, Y. Shinoda, Y. Yabuki, K. Fukunaga, J. Aoki, T. Noguchi and A. Matsuzawa, J. Biol. Chem., 2017, 292, 8174-8185.

6 R. Micha and D. Mozaffarian, Nat. Rev. Endocrinol., 2009, 5, 335-344.

7 T. Monguchi, T. Hara, M. Hasokawa, H. Nakajima, K. Mori, R. Toh, Y. Irino, T. Ishida, K. I. Hirata and M. Shinohara, Journal of Cardiology, 2017, 70, 121-127.

8 A. H. Lichtenstein, Curr. Atheroscler. Rep., 2014, 16, 433.

9 A. Motard-Bélanger, A. Charest, G. Grenier, et al., Am. J. Clin. Nutr., 2008, 87, 593.

10 I. A. Brouwer, A. J. Wanders and M. B. Katan, PLoS One, 2010, 5, e9434.

11 E. Choe and D. B. Min, Compr. Rev. Food Sci. Food Saf., 2010, 5, 169-186.

12 A. A. Christy, Z. Xu and P. B. Harrington, Chem. Phys. Lipids, 2009, 158, 22-31.

13 A. Reis and C. M. Spickett, Biochim. Biophys. Acta, Biomembr., 2012, 1818, 2374-2387.

14 E. Koh and J. Surh, Food Chem., 2015, 174, 467-472.

15 D. M. Meacher and D. B. Menzel, Cell Biol. Toxicol., 1999, 15, 163-171.

16 L. R. Tovar and T. Kaneda, J. Jpn. Oil Chem. Soc., 1977, 26, 169-172.

17 S. T. Da and P. A. Pereira, J. Agric. Food Chem., 2008, 56, 3129.

18 P. M. Eckl and N. Bresgen, Free Radical Biol. Med., 2017, 111, 244-252.

19 Y. Cho, M. K. Song, T. S. Kim and J. C. Ryu, Environ. Pollut., 2017, 229, 810-817.
20 G. Boskou, F. N. Salta, A. Chiou, E. Troullidou and N. K. Andrikopoulos, Eur. J. Lipid Sci. Technol., 2006, 108, 109-115.

21 A. Li, B. Yuan, W. Li, F. Wang and Y. Ha, Chem. Phys. Lipids, 2013, 166, 55-60.

22 C. Li, Y. Zhang, S. Li, G. Wang, C. Xu, Y. Deng and S. Wang, J. Agric. Food Chem., 2013, 61, 10392-10397.

23 C. Li, Y. Yao, G. Zhao, W. Cheng, H. Liu, et al., J. Agric. Food Chem., 2011, 59, 12493-12498.

24 W. Liu, G. Lu, G. Yang and Y. Bi, Fuel, 2019, 242, 133-139.

25 M. J. Frisch, G. W. Trucks, H. B. Schlegel, G. E. Scuseria, M. A. Robb, J. R. Cheeseman, et al., Gaussian 09, Revision B.1, Gaussian, Inc., Wallingford, CT, 2009.

26 Y. Chen, Y. Yang, S. Nie, X. Yang, Y. Wang, M. Yang, C. Li and M. Xie, Food Control, 2014, 44, 191-197.

27 E. Choe and D. B. Min, J. Food Sci., 2010, 72, R77-R86.

28 W. Tsuzuki, Chem. Phys. Lipids, 2010, 163, 741-745.

29 E. N. Frankel, Chemistry of Autoxidation: Mechanism, Products and Flavor Significance, in Flavor Chemistry of Fats and Oils, ed. D. B. Min and T. H. Smouse, Am. Oil Chem. Soc., Champaign, IL, 1985, pp. 1-37.

30 Q. Guo, F. He, Q. Li, Z. Deng, J. Jin and Y. Ha, Food Control, 2016, 67, 255-264.

31 A. A. Christy, Lipids, 2009, 44, 1105-1112.

32 W. E. Neff, K. Warner and W. C. Byrdwell, J. Am. Oil Chem. Soc., 2000, 77, 1303-1314.

33 L. C. S. Bastos, E. A. de Almeida Costa and P. A. P. Pereira, Food Chem., 2017, 218, 518-524.

34 C. C. Akoh and D. B. Min, Rev. Bras. Cienc. Farm., 2002, 40, 112-113. 